\title{
Catálogo de las obras de teatro del siglo XVIII que se conservan en la Biblioteca del MuVIM (Valencia)
}

\author{
Ana M. ${ }^{a}$ ReIg FERRER, \\ Benedicta Chilet Llácer, \\ Sergio Vilata Menadas
}

Biblioteca del Museu Valencià de la Il-lustració i de la Modernitat, MuVIM

CES.XVIII, núm. 18 (2008), págs. 147-179. 
Resumen: Para dar a conocer las obras de teatro del siglo XVIII, que se conservan en la Biblioteca del MuVIM, se ha elaborado un catálogo alfabético de autores y obras anónimas, seguido de un índice de títulos.

Palabras clave: Teatro. Siglo XVIII. Catálogo. Sainetes. Comedias.

$$
-148-
$$


En 1986 el Archivo-Biblioteca de la Diputación de Valencia adquirió, de un librero de viejo, un total de 2.390 obras de teatro, cuya cronología abarcaba los siglos XVIII al XX.

El objetivo del presente trabajo es dar a conocer las obras teatrales del siglo XVIII que se conservan en la biblioteca del MuVIM (Museu Valencià de la Il-lustració i de la Modernitat), entidad que, desde 2001, ha asumido la función de biblioteca general de la Diputación de Valencia.

Este fondo, formado sobre todo por sainetes y comedias, procedía, en su mayor parte, de antiguos teatros de la ciudad de Valencia, concretamente de los teatros Ruzafa (fundado en 1868) y Eslava (en 1908). El sello de aquellos centros aparece en muchas portadas de las obras de los siglos XIX y XX, junto con anotaciones manuscritas de cambios de texto y de personajes, que indica que fueron obras representadas. En cambio, las obras del XVIII no cuentan con ningún indicio que demuestre ni su procedencia ni su posible representación.

El catálogo que presentamos está formado por 164 obras impresas a lo largo del siglo XVIII, tomando como fecha final 1808, fin del reinado de Carlos IV. Se trata de un conjunto de obras sueltas que en algún momento estuvieron encuadernadas juntas, con el título genérico de Comedias, Sainetes, etc., pero que nos han llegado, en su mayoría, desencuadernadas.

La descripción de las obras la hemos realizado siguiendo las normas de catalogación para bibliotecas. El resultado es un catálogo alfabético de autores y obras anónimas. La mayoría de estas obras carecen de portada propia y el título se ha tomado de la primera página. Las anónimas se han encabezado directamente por la primera palabra del título.

Al respetar el orden y la grafía del título, muchas de ellas empiezan por el género: comedia, entremés, sainete, etc., que es la parte que precede al título propiamente dicho. Por este motivo, al final del catálogo, hemos elaborado un índice, para una más cómoda consulta.

En cuanto a la fecha de impresión, aunque algunas obras carecen de año, sus características tipográficas nos han permitido datarlas en el siglo XVIII. 
Pasando al análisis de los contenidos, una primera revisión nos permite observar lo que ya advirtió en su día Rodríguez-Solís ${ }^{1}$ : el género teatral sufre un importante cambio a lo largo del siglo XVIII, los famosos autos sacramentales ya no interesaban al público, como tampoco las tragedias; el teatro estaba pidiendo a gritos una reforma. Estos rasgos son perfectamente perceptibles en el conjunto del catálogo, pues apenas encontramos tragedias ni autos sacramentales y la gran proliferación de comedias de mediados de siglo da paso, a finales de éste, a una abundancia de sainetes.

A pesar de que en la mayoría de estos sainetes no consta ni autor ni impresor, el estudio de Fernández Gómez ${ }^{2}$ nos ha permitido atribuir al impresor Benito Cano muchas de las obras impresas en 1791, que se vendían en la madrileña librería de Quiroga y deducir la autoría de algunos sainetes, que aparecen como anónimos, como algunos atribuidos a Ramón de la Cruz.

Según Rodríguez-Solís, al igual que Goya supo reflejar en sus cuadros no sólo sus propios sentimientos sino también las ideas y deseos de la sociedad de su época, don Ramón de la Cruz reflejó, en sus sainetes, las costumbres de la sociedad de finales de siglo, aunque su intencionalidad era el simple entretenimiento del público.

Tanto es así que Pérez Galdós llegó a decir que «en la sociedad originalísima de sus sainetes, se oyen los primeros rugidos de la revolución francesa, precursora de grandes trastornos fuera y dentro de España...» ${ }^{3}$.

Con el presente catálogo queremos dar a conocer las obras teatrales que conservamos en nuestra biblioteca y contribuir a incrementar la disponibilidad de las fuentes bibliográficas para la investigación de los gustos teatrales del XvIII.

\section{Catálogo}

1

Alboreda, Alejandro (1650-ca.1700)

Comedia Famosa El arco de la paz del cielo, Sta. Bárbara / de Don Joseph de Arboreda.—En Madrid: en la imprenta de Antonio Sanz, 1751.—36 págs.; 4. ${ }^{\circ}$ Autor también llamado Arboleda, Alejandro.
Tít. tomado de la primera pág.

Precede al tít. «Núm.34».

Datos de publicación tomados del colofón. Sign.: A-D4, E2

Texto a dos col., 48 líneas y reclamos. T-70/1(09)

\footnotetext{
1 Enrique Rodríguez-Solís, Majas, manolas y chulas: historia, tipos y costumbres de antaño y ogaño, Madrid, [s. n.], 1886.

2 Juan F. Fernández Gómez, Catálogo de entremeses y sainetes del siglo XVIII, Oviedo, IFES, 1993.

3 Rodríguez-Solís, op. cit., pág. 43.
} 
Añorbe y Corregel, Tomás de

Comedia famosa, La oveja contra el pastor, y el tyrano Boleslao/ de D. Thomas de Añorbe y Corregel.—En Madrid: en la Imprenta de Antonio Sanz..., 1746.[32] págs.; 4. ${ }^{\circ}$

Precede al tít.: «Núm. 174».

El pie de imp. consta en colofón.

Sign.: A-D4

Texto a dos col.

$\mathrm{T}-76 / 31$

3

Auto al nacimiento de nuestro Señor Jesu-Christo, intitulado Las astucias de Luzbel contra las divinas profecías.[S. l.: s. n., 17--?].— 28 págs.; $4 .^{\circ}$

Tít. tomado de la primera pág.

Texto a dos col., 49 líneas y reclamos.

Sign.: A-C4, D2

$\mathrm{T}-73 / 44$

4

Bances Candamo, Francisco Antonio de (1662-1709)

Comedia famosa, El duelo contra su damal de Don Francisco Vances y Candamo.En Madrid: en la imprenta de Antonio Sanz..., 1733.— [38] págs.; 4. ${ }^{\circ}$

Precede al tít.: «Núm. 129»

El pie de imprenta consta en colofón.

Texto a dos col., 48 líneas y reclamos.

Sign.: A-D4, E3

$\mathrm{T}-73 / 59$

5

Belmonte Bermúdez, Luis de
Comedia famosa, El diablo predicador y mayor contrario amigo/ de un Ingenio de esta corte.- Barcelona: en la imprenta de Carlos Sapera: véndese en su casa ... y en la de Francisco Suriá ..., 1764.— [36] págs.; 4. ${ }^{\circ}$

Precede al tít.: «Núm. 111».

Nombre real del autor: Luis de Belmonte Bermúdez (Alborg).

El pie de imp. consta en colofón.

Sign.: A-D4, E2

Texto a dos col.

T-76/26

6

Calderón de la Barca, Pedro (1600-1681) Comedia famosa. Las canas en el papel y dudoso en la venganza/ De Don Pedro Calderón de la Barca._Zaragoza: en la Imprenta que está en la plaza del Carbon sobre el Peso Real..., [17--?].36 págs.; $4 .^{\circ}$

Precede al tít.: «Núm. 14».

Datos de publicación en el colofón.

Sign.: A-D4, E2

Texto en verso y a dos col., 40 líneas, reclamos.

Anotaciones ms.

T-73/08

7

Calderón de la Barca, Pedro (1600-1681)

Comedia famosa, Un castigo en tres venganzas/ de don Pedro Calderón de la Barca. - Barcelona: por Francisco Suria y Burgada, ..., [ca.1770].[16] h.; $4 .^{\circ}$

Tít. tomado de la primera pág.

Precede al tít.: «Núm. 103». 
El pie de imprenta consta en colofón.

Francisco Suria i Burgada ejerce como impresor entre 1770 y 1805.

Sign.: A-D4

2 cols., 51 lín. y reclamos.

$\mathrm{T}-68 / 31$

8

Calderón de la Barca, Pedro (1600-1681)

Comedia famosa. Con quien vengo vengo/ de Pedro Calderón de la Barca.Valencia: en la Imprenta de Joseph y Thomas de Orga, 1782.— 38 págs.; 4. ${ }^{\circ}$

Precede al tít. «Núm. 269».

Datos de publicación tomados del colofón.

Sig.: A-D4, E3

Texto a dos col.

$\mathrm{T}-76 / 28(1)$

9

Calderón de la Barca, Pedro (1600-1681)

Comedia famosa, La estatua de Prometeo: representose a los años de la Reyna Madre Nuestra Señora/ Don Pedro Calderón de la Barca. - Barcelona: por Francisco Suria y Burgada, 1765.[32] págs.; 4. ${ }^{\circ}$

Precede al tít.: «Núm. 65».

Datos de publicación tomados del colofón

Sign.: A-D4

T-76/16

10

Calderón de la Barca, Pedro (1600-1681)

Comedia famosa. El mercader de Toledo: vara de medir, y acción del mejor testigol de don Pedro Calderón de la Barca.Sevilla: en la Imprenta de Joseph Padrino, [17--?].— 24 págs.; 4. ${ }^{\circ}$
Tít. tomado de la primera pág.

Precede al tít.: «Núm. 134».

Joseph Padrino ejerce ca.: 1748-1765.

Datos de publicación tomados del colofón.

Sign.: A-C4

Texto a dos col.

$\mathrm{T}-76 / 2$

11

Calderón de la Barca, Pedro (1600-1681)

Comedia famosa, No hay cosa como callarl De Don Pedro Calderón de la Barca.Barcelona: por Francisco Suria y Burgada, ...: a costas de la Compañía, [1770-1805].- [36] págs.; 4. ${ }^{\circ}$

Precede al tít. «Núm. 77».

Tít. tomado de la primera pág.

Francisco Suriá y Brugada ejerce como impresor ca.: 1770-1805.

Datos de publicación en el colofón.

Sign.: A-D4, E2

Texto en verso y a dos col., 50 líneas, reclamos.

T-68/49

12

Calderón de la Barca, Pedro (1600-1681)

Comedia famosa. Para vencer a amor, querer vencerle: fiesta que se representó à sus Majestades en el salón de su Real Palacio/ de don Pedro Calderón de la Barca. - Sevilla: en la Imprenta de Joseph Padrino, [17--?].— 32 pág.; 4. ${ }^{\circ}$

Precede al tít. «Núm. 194».

Joseph Padrino ejerce ca.: 1748-1765.

Los datos de publicación constan en el colofón.

Sign.: A-D4

Texto a dos col. 
$\mathrm{T}-76 / 55$

13

Calderón de la Barca, Pedro (1600-1681)

Comedia famosa. El purgatorio de San Patricio/ de Don Pedro Calderón de la Barca. - Barcelona: por Francisco Suria y Burgada ..., [17--?].— [32] págs.; $4 .^{\circ}$

Tít. tomado de la primera pág.

Precede al tít.: «Núm. 3».

Fecha aproximada, 1770-1805, deducida de la época de ejercicio del impresor.

El pie de imp. consta en colofón.

Sign.: A-D4, E2

Texto a dos col. y en verso

$\mathrm{T}-76 / 32$

14

Calderón de la Barca, Pedro (1600-1681)

Comedia famosa, La púrpura de la rosal de D. Pedro Calderón de la Barca.En Barcelona: ... en la de Francisco Suriá..., 1764 (en la Imprenta de Carlos Sapera).— [16] pág.; 4. ${ }^{\circ}$

Precede al tít.: «Núm. 34».

Tít. tomado de la primera pág.

Datos de publicación tomados del colofón.

Sign.: A-D4

Texto a dos col. y reclamos.

T-73/19

15

Calderón de la Barca, Pedro (1600-1681)

Comedia famosa. El secreto a voces/ de don Pedro Calderón de la Barca.Valencia: en la Imprenta de Agustín Laborda..., 1775.— 40 págs.; 4. ${ }^{\circ}$

Tít. tomado de la primera pág.
Pie de imp. consta en colofón.

Sign.: A-E4

T-77/17

16

Calderón de la Barca, Pedro (1600-1681)

Comedia famosa. Las tres justicias en unal de don Pedro Calderón de la Barca.Barcelona: en la imprenta de Francisco Suriá: vendese en su casa y en la de Carlos Sapera, 1771.— [32] págs.; 4. ${ }^{\circ}$

Precede a tít.: «Núm. 101».

El pie de imp. consta en colofón.

Sign.: A-D4

Texto a dos col.

$\mathrm{T}-76 / 28(2)$

17

Calderón de la Barca, Pedro (1600-1681)

Comedia famosa, La vida es sueño/ de

Don Pedro Calderón de la Barca._- En

Valencia: en la Imprenta de la Viuda de Joseph de Orga ..., 1761._- 36 págs.; $4 .^{\circ}$

Precede al tít.: «Núm.l».

Tít. tomado de la primera pág.

Datos de publicación tomados del colofón.

Sign.: A-D4, E2

Texto a dos col.

T-68/51

18

Calderón de la Barca, Pedro (1600-1681)

Comedias del celebre poeta español Don Pedro Calderón de la Barca.../ que saca a la luz Don Juan Fernandez de Apontes ...; tomo segundo.- (En Madrid: en la oficina de la Viuda de Don Manuel Fernández, e Imprenta del 
Supremo Consejo de la Inquisición: se hallará ... en la Tienda de Provincia ..., 1760.— [4], 496 págs.; 4. ${ }^{\circ}$

Contiene: Céfalo y Pocris-El castillo de Lindabridis - Bien vengas mal - La vida es sueño-Casa con dos puertasEl purgatorio de San Patricio_ L La gran Cenobia - La devoción de la Cruz-La puente de Mantible - Saber del mal y del bien-Fineza contra fineza.

Sign.: 3, A-Z4, 2A-2Z4, 3A-3Q4

Texto a una y dos col.

Port. con grab. xil.

T-77/6

19

Calderón de la Barca, Pedro (1600-1681)

La gran comedia. Amigo, amante, y leal/

de Don Pedro Calderón de la Barca.[S. 1.: s. n., 17--?].- págs. 49-93; 4. ${ }^{\circ}$

Tít. tomado de la primera pág.

Texto a dos col. y reclamos.

Sign.: G-H4, M2

$\mathrm{T}-73 / 13(1)$

20

Calderón de la Barca, Pedro (1600-1681)

La gran comedia. Basta callar/ de Don Pedro Calderón de la Barca.- - [S. l.: s. n., 17--?].— págs. 94-140; 4. ${ }^{\circ}$

Tít. tomado de la primera pág.

Texto a dos col. y reclamos.

Sign.: M2, G-Q4, S2

$\mathrm{T}-76 / 56(2)$

21

Calderón de la Barca, Pedro (1600-1681)

La gran comedia. Darlo todo, y no dar nada: Fiesta que se representó a sus
Magestades en el Salón de su Real Palacio/ de Don Pedro Calderón de la Barca.-[S. 1.: s. n., 17--?].págs. 45-100; $4 .^{\circ}$

Texto a dos col. y reclamos.

Sign.: F2, G-M4, N2

$\mathrm{T}-73 / 11$

22

Calderón de la Barca, Pedro (1600-1681)

La gran comedia. La desdicha de la vozl de Don Pedro Calderón de la Barca.[S. 1.: s. n., 17--?].— págs. 101-148; 4. Tít. tomado de la primera pág.

Texto a dos col. y en verso, 41 líneas y reclamos.

Sign.: A-S4, T2

$\mathrm{T}-73 / 12$

23

Calderón de la Barca, Pedro (1600-1681)

La gran comedia. El escondido y la tapadal de Don Pedro Calderón de la Barca.[S. 1.: s. n., 17--?].— págs. 437-480; 4. Texto a dos col., 41 líneas y reclamos.

Sign.: 3J2, 3K-3N4, 304

$\mathrm{T}-73 / 50$

24

Calderón de la Barca, Pedro (1600-1681)

La gran comedia. La exaltacion de la cruz/ de Don Pedro Calderón de la Barca.[S. 1.: s. n., 17--?].- págs. 306-351; 4. ${ }^{\circ}$

Texto a dos col. y en verso, 41 líneas y reclamos.

Sign.: 2Q3, 2R-2X4

$\mathrm{T}-73 / 47(3)$ 
25

Calderón de la Barca, Pedro (1600-1681)

La gran comedia. La fiera, el rayo, y la piedra: Fiesta Real que se hizo à sus Majestades en el Coliseo de Buen Retiro/ de Don Pedro Calderón de la Barca.[S. 1.: s. n., 17--?].— págs. 400-528; $4 .^{\circ}$

Texto a dos col. y en verso, reclamo.

Sign.: [3N]2-3E4, 3F2

$\mathrm{T}-73 / 15(2)$

\section{6}

Calderón de la Barca, Pedro (1600-1681)

La gran comedia. Fuego de Dios en el querer bien/ de Don Pedro Calderón de la Barca.- [S. 1.: s. n., 17--?].págs. 201-247; $4 .^{\circ}$

Tít. tomado de la primera pág.

Texto a dos col., 42 líneas y reclamos.

Sign.: 2C-2G4, $2 \mathrm{H} 3$

$\mathrm{T}-73 / 47(1)$

27

Calderón de la Barca, Pedro (1600-1681)

La gran comedia. El laurel de Apolo: Fiesta de Zarzuela, Transferida al Real Coliseo de Buen Retiro/ de Don Pedro Calderón de la Barca. - [S. 1.: s. n., 17--?].— págs. 377-412; $4 .^{\circ}$

Tít. tomado de la primera pág.

Texto a dos col. y reclamos.

Sign.: 3B-3E4, 3F2

T-73/09

28

Calderón de la Barca, Pedro (1600-1681)

La gran comedia. No hay cosa como callarl de Don Pedro Calderón de la Barca.-
[S. 1.: s. n., 17--?].— pág. 306 [sic 352] $-398 ; 4 .^{\circ}$

Tít. tomado de la primera pág.

Texto a dos col. y en verso, 41 líneas y reclamos.

Sign.: 2Y-3D3

$\mathrm{T}-73 / 47(4)$

29

Calderón de la Barca, Pedro (1600-1681)

La gran comedia. El pintor de su deshonral de Don Pedro Calderón de la Barca.[S. 1.: s. n., 17--?].— págs. 149-192; 4. ${ }^{\circ}$

Tít. tomado de la primera pág.

Texto a dos col., 41 líneas y reclamos.

Sign.: U2, V-2A4

T-73/48

30

Calderón de la Barca, Pedro (1600-1681)

La gran comedia. El segundo scipion: fiesta que se representó à los años del Rey nuestro Señor Don Carlos Segundo/ de Don Pedro Calderón de la Barca.[S. 1.: s. n., 17--?].— págs. 248-305; 4. ${ }^{\circ}$

Tít. tomado de la primera pág.

Texto a dos col., 41 líneas y reclamos.

Sign.: 2H4, 2H-2P4, 2Q

$\mathrm{T}-73 / 47(2)$

31

Calderón de la Barca, Pedro (1600-1681)

La gran comedia. Tambien hay duelo en las damas/ de Don Pedro Calderón de la Barca.- [S. l.: s. n., 17--?].págs. 413-399; $4 .^{\circ}$

Tít. tomado de la primera pág.

Texto a dos col. y reclamos.

Sign.: 3E2, 3G-3M4, 3N2 
$\mathrm{T}-73 / 15(1)$

32

Calderón de la Barca, Pedro (1600-1681)

Loa para la comedia Los tres mayores prodigios: Fiesta que se representó à sus magestades, en el Real Sitio de la Casa del Campo/ de D. Pedro Calderón de la Barca.— [S. l.: s. n., 17--?].págs. 309-376; $4 .^{\circ}$

Tít. tomado de la primera pág.

Texto a dos col. y en verso, reclamos.

Sign.: 2Q2, 2R-3A4,

$\mathrm{T}-73 / 10$

33

Calderón de la Barca, Pedro (1600-1681)

Mañana será otro día: comedia famosal de Don Pedro Calderón de la Barca.Barcelona: por Francisco Suria y Burgada...: costas de la Compañía, [1770-1805].— [36] págs.; 4. ${ }^{\circ}$

Francisco Suriá y Burgada ejerce como impresor ca.: 1770-1805.

Sign.: A-D4, E2

$\mathrm{T}-68 / 43$

34

CañIZares, José de (1676-1750)

Comedia famosa, Carlos Quinto sobre Tunez/ de don Joseph de Cañizares.En Valencia: en la Imprenta de la Viuda de Orga..., 1770.—34 págs.; 4. ${ }^{\circ}$

Precede al tít.: «Núm. 167».

Título tomado de la primera pág.

Datos de publicación tomados del colofón.

Sign.: A-D4

Texto a dos col., 49 líneas y reclamos.
Sello «Librería de Josef Carlos... Lonja de la Seda».

\section{T-68/2}

\section{5}

CañIZares, José de (1676-1750)

Comedia famosa, El domine Lucas/ de Don Josheph de Cañizares. - En Madrid: en la imprenta de Antonio Sanz..., 1746. - [32] págs.; 4. ${ }^{\circ}$

Precede al tít.: «Núm. 24».

El pie de imprenta consta en colofón.

Texto a dos col., 53 líneas y reclamos.

Sign.: A-D4

$\mathrm{T}-73 / 58$

36

Cañ̃zares, José de (1676-1750)

Comedia famosa, También por la voz hay dicha/ de Don Joseph de Cañizares.Sevilla: en la imprenta de Manuel Nicolás Vázquez ..., [17--?].— [36] págs.; $4 .^{\circ}$

Precede al tít.: «Núm. 12».

El pie de imprenta consta en colofón.

Texto a dos col.

Sign.: A-D4, E2

$\mathrm{T}-77 / 19$

\section{7}

Cañizares, José de (1676-1750)

Comedia famosa. También por la voz hay dicha/ de Don Joseph de Cañizares.En Madrid: en la imprenta de Antonio Sanz..., 1746.- [40] págs.; 4. ${ }^{\circ}$

Precede al tít.: «Núm. 258».

El pie de imprenta consta en colofón. Texto a dos col., 48 líneas y reclamos. Sign.: A-E4 
$\mathrm{T}-73 / 07$

\section{8}

CañIZares, José de (1676-1750)

Tragedia El Sacrificio de Ifigenia: en cinco actos/ de Don Joseph de Cañizares; primera parte.- Corregida y enmendada en esta segunda impresion.- Barcelona: En la Imprenta de Carlos Gibert y Tutó..., [1775-1796].— 28 págs.; 4. ${ }^{\circ}$

Tít. tomado de la primera pág.

Precede al tít.: «Núm. 126».

Datos de publicación tomados del colofón.

Fechas de la actividad conocida del impresor de 1775 a 1796.

Sign.: A-C4, D2

Texto a dos col., 46 líneas, reclamos.

T-68/61(1)

\section{9}

CañIZARes, José de (1676-1750)

Tragedia El Sacrificio de Ifigenia: en cinco actos/ de Don Joseph de Cañizares; segunda parte.- Corregida y enmendada en esta segunda impresión.Barcelona: En la Imprenta de Carlos Gibert y Tutó..., [1775-1796].— 31 págs.; $4 .^{\circ}$

Tít. tomado de la primera pág.

Precede al tít.: «Núm. 127».

Datos de publicación tomados del colofón

Fechas de la actividad conocida del impresor de 1775 a 1796.

Sign.: A-D4

Texto a dos col., 46 líneas, reclamos. T-68/61(1)

40

Castrillón, F. E.
Defensa de Valencia y castigo de traydores: Comedia nueva original en cuatro actos. - Madrid: En la librería de la viuda de Quiroga, [ca.1808].— 30 págs.; 4. ${ }^{\circ}$

Representada en el Teatro de la calle de la Cruz el dia 19 de octubre de 1808.

T-68/33

41

Coello, Antonio (1600?-1652)

Comedia famosa, El catalán Serrallonga y vandos de Barcelona/ de Tres ingenios, la primera jornada de don Antonio Coello, la segunda de don Francisco de Roxas y la tercera de Luis Vélez de Guevara.- Barcelona: en la imprenta de Juan Nadal: a costas de la Compañía, 1770.— [18] h.; 4. ${ }^{\circ}$

Precede al tít.: «Núm. 206».

El pie de imp. consta en colofón.

T-68/29

42

Cordero, Jacinto (1606-1646)

Comedia famosa. El juramento ante Dios y lealtad contra el amor/ del alférez Jacinto Cordero.- Barcelona: en la imprenta de Francisco Suria: a costas de la Compañía, 1770.— [28] págs.; 4. ${ }^{\circ}$

Precede al tít.: «Núm. 148».

El pie de imp. consta en colofón.

T-76/30

43

Cordero, Pedro

El príncipe jardinero y mayor ciencia laureada: comedia americanal De Don Pedro Cordero.- En Sevilla: 
en la Imprenta de Joseph Padrino..., [17--?].- 40 págs.; $4 .^{\circ}$

Según Gutiérrez del Caño, José Padrino ejerce $c a$. 1748-1775.

Tít. tomado de la primera pág.

Texto a dos col.

Sign.: A-E4

T-16/13

44

CrébILlon, Claude-Prosper Jolyot de

Rhadamisto y Zenobia: tragedia francesal de Monsieur De Crebillon... ofrécela al teatro español D. A. B. N.- [S.l.: s.n., 17--?].— 78 págs.; $14 \mathrm{~cm}$.

Sign.: A-E8

T-80/23

45

Cruz Cano y Olmedilla, Ramón de la (1731-1794)

Manolo: Tragedia para reir, ò Saynete para llorar: primera parte.- Barcelona: Por Carlos Gibert y Tutó; Se hallará en Madrid: en la Librería de Quiroga..., 1792.- 16 págs.; 4. ${ }^{\circ}$

Texto en verso, reclamos.

Sign.: A8

Grab. xil. en port.

T-73/21

46

Cruz Cano y Olmedilla, Ramón de la

(1731-1794)

Saynete, intitulado El almacen de novias: representado en los teatros de esta corte para diez personas. - Madrid: [Benito Cano] Se hallará en la Librería de Quiroga..., 1791.— 12 págs.; 4. ${ }^{\circ}$
Texto a dos col., 36 líneas y reclamos.

Sign.: A6

Grab. xil. en port.

T-73/61

47

Cruz Cano y Olmedilla, Ramón de la (1731-1794)

Saynete, intitulado La avaricia castigada o Los segundones: representado en los teatros de esta corte para ocho personas._Madrid: [Benito Cano] Se hallará en la Librería de Quiroga..., 1791.— 12 págs.; $4 .^{\circ}$

Texto a dos col., 43 líneas y reclamos.

Sign.: A6

Grab. xil. en port.

T-73/26

48

Cruz Cano y Olmedilla, Ramón de la (1731-1794)

Saynete, intitulado El caballero de Medina: representado en los teatros de esta Corte para trece personas.- En Madrid: [Benito Cano] Se hallará en la Librería de Quiroga..., 1791._ 12 págs.; $4 .^{\circ}$

Sign.: A6

Texto a dos col.

Grab. xil. en port.

T-76/25

49

Cruz Cano y Olmedilla, Ramón de la (1731-1794)

Saynete, intitulado El casado por fuerza: representado en los teatros de esta Corte para once personas.- En Madrid: 
[Benito Cano] Se hallará en la Librería de Quiroga..., 1791.— 11 págs.; 4. ${ }^{\circ}$

Sign.: A7

Texto a dos col.

Grab. xil. en port.

T-76/10

50

Cruz Cano y Olmedilla, Ramón de la (1731-1794)

Saynete, intitulado El casero burlado.-

En Madrid: [Benito Cano] Se hallará en la Librería de Quiroga..., 1791.8 págs.; $4 .^{\circ}$

Sign.: a4

Texto a dos col.

T-76/43(1)

51

Cruz Cano y Olmedilla, Ramón de la (1731-1794)

Saynete, intitulado El cochero y monsieur corneta.- En Madrid: [Benito Cano] Se hallará en la Librería de Quiroga..., 1791. —8 págs.; 4. ${ }^{\circ}$

Sign.: a4

Texto a dos col.

$\mathrm{T}-76 / 43(2)$

52

Cruz Cano y Olmedilla, Ramón de la (1731-1794)

Saynete, intitulado La cuenta de propios y arbitrios: representado en los teatros de esta Corte para ocho personas.- En Madrid: [Benito Cano] Se hallará en la Librería de Quiroga..., 1791._ 8 págs.; $4 .^{\circ}$

Sign.: a4
Texto a dos col.

Grab. xil. en port.

T-76/39

53

Cruz Cano y Olmedilla, Ramón de la (1731-1794)

Saynete, intitulado El enfermo fugitivo ó

La geringa: representado en los teatros de esta corte para trece personas.Madrid: [Benito Cano] Se hallará en la Librería de Quiroga..., 1791._12 págs.; $4 .^{\circ}$

Texto a dos col., 36 líneas y reclamos.

Sign.: A6

Grab. xil. en port.

$\mathrm{T}-73 / 27$

54

Cruz Cano y Olmedilla, Ramón de la (1731-1794)

Saynete, intitulado Gracioso engaño creido del duende fingido: representado en los teatros de esta corte para nueve personas._Madrid: [Benito Cano] Se hallará en la Librería de Quiroga..., 1791._12 págs.; $4 .^{\circ}$

Texto a dos col., 40 líneas y reclamos.

Sign.: A6

Grab. xil. en port.

$\mathrm{T}-73 / 31$

55

Cruz Cano y Olmedilla, Ramón de la (1731-1794)

Saynete ó tragedia burlesca El Manolo: segunda parte: representado en los teatros de esta corte, para siete personas.- 
Madrid: en la Librería de Quiroga..., 1791.— 8 págs.; 4. ${ }^{\circ}$

Atribuida a Ramón de la Cruz?

Texto en verso, reclamos.

Sign.: A6

Grab. xil. en port.

$\mathrm{T}-73 / 23$

\section{6}

Cubillo De Aragon, Álvaro (1596?-1661)

Comedia famosa. El rayo de Andalucía y jenizaro de España: primera partel de Don Álvaro Cuvillo de Aragón.- En Salamanca: en la imprenta de Santa Cruz..., [17--?].— 32 págs.; 4. ${ }^{\circ}$

Tít. y mención de responsabilidad obtenidos del epígrafe, le precede: «Núm. 71».

Pie de imp. tomado del colofón.

Imprenta de la Santa Cruz ejerce ca. 1777-1785, según Gutiérrez del Caño.

Sign.: A-D4

Texto a dos col.

T-76/35

57

Cubillo De Aragon, Álvaro (1596?-1661)

Comedia famosa. El rayo de Andalucía y jenízaro de España: segunda partel de Don Álvaro Cuvillo de Aragón.- En Salamanca: en la imprenta de Santa Cruz..., [17--?].— 25 págs.; 4. ${ }^{\circ}$

Tít. y mención de responsabilidad obtenidos del epígrafe, le precede: «Núm. 72».

Pie de imp. tomado del colofón.

Imprenta de la Santa Cruz ejerce $c a$. 1777-1785, según Gutiérrez del Caño. Sign.: A-C4, D2
Texto a dos col.

T-76/37

\section{8}

Diamante, Juan Bautista (ca. 1630ca.1685)

Comedia Famosa El negro mas prodigioso/ de Don Juan Bautista Diamante.- En Valencia: en la Imprenta de la Viuda de Joseph de Orga..., 1763.— 34 págs.; $4 .^{\circ}$

Fechas asociadas al autor (1625-1687), fuente BN.

Precede al tít.: «Núm. 55».

Título tomado de la primera pág.

Datos de publicación tomados del colofón.

Sign.: A-D4

Texto a dos col.

T-68/16

59

Enríquez Gómez, Antonio (1600-1663)

Comedia famosa, A lo que obligan los zelos/ de Don Fernando Zerate.- Barcelona: Por Francisco Suria y Burgada,...: A costas de la Compañia, [ca. 1770].[32] págs.; 4. ${ }^{\circ}$

Enríque Gómez, Antonio (1600-1663) es seudónimo de: Enríquez, Antonio; Enríquez de Paz; Henríquez Gómez, Antonio; Henrríquez Gómez, Antonio; Zárate, Fernando de; Zárate y Castronovo, Fernando de.

Tít. tomado de la primera pág.

Precede al tít.: «Núm. 165».

Datos de publicación tomados del colofón. Sign.: A-D4

Dos columnas, 44 líneas, reclamos. T-68/41 
60

Enríquez Gómez, Antonio (1600-1663)

Comedia famosa Antes que todo es mi amigo/ de Fernando de Zárate. - En Valencia: en la imprenta de Joseph y Thomás de Orga, calle de la Cruz Nueva..., 1777.— 28 págs.; 4. ${ }^{\circ}$

Precede al tít.: «Núm. 215».

Pie de imp. consta en colofón.

Sign.: A-C4, D2

Texto a dos col.

$\mathrm{T}-77 / 18$

61

EnRíouez Gómez, Antonio (1600-1663)

Comedia famosa, El maestro de Alexandro/ de... Fernando Zárate.- Valencia: Imprenta de los hermanos Orga, 1792.— 36 págs.; 4. ${ }^{\circ}$

Enríque Gómez, Antonio (1600-1663) es seudónimo de: Enríquez, Antonio; Enríquez de Paz; Henríquez Gómez, Antonio; Henrríquez Gómez, Antonio; Zárate, Fernando de; Zárate y Castronovo, Fernando de.

Precede al tít. «Núm. 132».

Tít. tomado de la primera pág.

Datos de publicación tomados del colofón.

Sign.: A-D4, E2

Texto a dos col., 49 líneas y reclamos. T-68/55(1)

62

Entremés de la Duca.- [S. l.: s. n., 17--?].— 8 págs.; $8 .{ }^{\circ}$

Tít. tomado de la primera pág.

T-77/4(11)
63

Entremés de las conclusiones.- [S. l.: s. n., 17--?].— 16 págs.; 8. ${ }^{\circ}$

Tít. tomado de la primera pág.

$\mathrm{T}-77 / 4(02)$

64

Entremés de los caldereros.- [S. l.: s. n., 17--?].— 16 págs.; 8.

Tít. tomado de la primera pág.

T-77/4(03)

65

Entremés de los vicios patentes.- [S. 1.: s. n., 17--?].— 16 págs.; 8. ${ }^{\circ}$

Tít. tomado de la primera pág.

T-77/4(07)

66

Entremés de trullo.- [S. 1.: s. n., 17--?].8 págs.; $8{ }^{\circ}$

Tít. tomado de la primera pág.

$\mathrm{T}-77 / 4(08)$

67

Entremés del gori-gori.— Valencia: Imprenta de Laborda, [17--?].8 págs.; $8{ }^{\circ}$

Según Gutiérrez del Caño, Agustín Laborda ejerce $c a$. 1734-1765.

Pie de imp. tomado del colofón.

Sign.: []4

Tít. tomado de la primera pág.

$\mathrm{T}-77 / 4(04)$

68

Entremés del molinero.- [S. l.: s. n., 17--?].— 16 págs.; 8. ${ }^{\circ}$

Tít. tomado de la primera pág. 
69

Entremés del pésame de Medrano.— [S. l.: s. n., 17--?].— 8 págs.; $8 .^{\circ}$

Tít. tomado de la primera pág. T-77/4(09)

70

Entremés La Requisitoria del borrico.[S. l.: s. n., 17--?].— 8 págs.; 8.

Tít. tomado de la primera pág.

T-77/4(06)

71

Entremés nuevo del capitán D. Samuel.-

[Valencia]: imprenta de Laborda, [s. a].- 8 págs.; $8 .^{\circ}$

Pie de imp. tomado del colofón.

Según Gutiérrez del Caño, Agustín

Laborda ejerce $c a$. 1734-1765.

Sign.: []4

Tít. tomado de la primera pág.

T-77/4(10)

72

Goldoni, Carlo (1707-1793)

Comedia en prosa La posadera y el enemigo de las mugeres: en tres actos.Barcelona: en la oficina de Pablo Nadal, 1798. - 28 págs.; $4 .^{\circ}$

Autor: Carlo Goldoni (Palau).

Precede al tít.: «Núm. 65».

Datos de publicación tomados del colofón.

Sign.: A-C4, D2

Texto a dos col.

T-76/22
González del Castillo, Juan Ignacio

Hannibal, escena lírica original ó Soliloquio unipersonal, en metro endecasílabo castellano.- Madrid: en la Librería de Manuel Quiroga..., 1791._ 16 págs.; $4 .^{\circ}$

Representada en el Coliseo de la Ciudad de Cádiz por el señor Luis Navarro.

Sign.: A8

Texto en verso, reclamos.

Grab. xil. en port.

$\mathrm{T}-73 / 14$

\section{4}

GonzÁlEz, Manuel

Comedia Famosa, El español Juan de Urbina/ del Lic. Manuel González.Madrid...: en la Imprenta de Antonio Sanz..., 1739.- [18] h.; 4. ${ }^{\circ}$

Original manuscrito con licencia de 1638, fuente: Catálogo de las piezas de teatro que se conserva en el Departamento de Manuscritos de la Biblioteca Nacional.

Tít. tomado de la primera pág.

Precede al tít.: «Núm. 188».

Datos de publicación en colofón.

Sign.: AD4, E2

Texto a dos col. y en verso, 47 líneas y reclamos.

T-70/1(11)

75

Ingenio, Un

Comedia Famosa. No hay cosa buena por fuerza/ de un ingenio.- [En Valencia: en la Imprenta de la viuda de Joseph de Orga..., 1772?].— 36 págs.; $4 .^{\circ}$

Precede al tít.: «Núm. 226». 
Título tomado de la primera pág.

Datos de publicación tomados del mismo título y autor extraidos del CCPB. Falta la última hoja que contiene el colofón.

Sign.: A-D4, E2

Texto a dos col., 49 líneas y reclamos.

T-68/26

76

Ingenio, Un

Comedia Famosa, La virtud consiste en medio, el pródigo y rico avariento/ de un ingenio. - En Valencia: en la Imprenta de la viuda de Joseph de Orga..., 1772.— 36 págs.; 4. ${ }^{\circ}$

Precede al tít.: «Núm. 173».

Título tomado de la primera pág.

Datos de publicación tomados del colofón.

Sign.: A-D4, E2

Texto a dos col.

T-68/14

\section{7}

INGENIO DE ESTA CORTE, Un

Comedia. Morir en la Cruz con Christo/ de un Ingenio de esta Corte.- [S.1.: s.n., 17--?].— 24 págs.; 4. ${ }^{\circ}$

Sign.: A-C4

Ejemp. falto de págs. finales.

Texto a dos col.

$\mathrm{T}-78 / 16$

\section{8}

IngENIO DE ESTA CORTE, Un

Comedia famosa, La Bandolera de Italia: y enemiga de los hombres/ de un ingenio de esta Corte. - Barcelona: Por Francisco Suria y Burgada...: A costas de la Compañía, [ca. 1770].— [40] págs.; 4. ${ }^{\circ}$
Tít. tomado de la primera pág.

Precede al tít.: «Núm. 239».

Datos de publicación tomados del colofón.

Sign.: A-E4

Texto a dos col., 44 líneas, reclamos.

T-68/45

79

INGENIO DE ESTA CORTE, Un

Comedia famosa, El falso nuncio de Portugal/ de un ingenio de esta corte.- En Madrid:... en la imprenta de Antonio Sanz..., 1741.— [36] págs.; 4. ${ }^{\circ}$

Precede al título: «Núm.14».

Tít. tomado de la primera pág.

El pie de imprenta consta en colofón.

Texto a dos col., 50 líneas y reclamos.

Sign.: A-D4, E2

$\mathrm{T}-73 / 35$

80

INGENIO DE ESTA CORTE, Un

Comedia famosa, Hados y lados hacen dichosos y desdichados/ de un ingenio.- En Valencia: en la imprenta de la Viuda de Joseph de Orga..., 1762._32 págs.; $4 .^{\circ}$

Precede al tít.: «Núm. 24».

Pie de imp. consta en colofón.

Sign.: A-D4

Texto a dos col.

T-76/6

81

IngENIO DE ESTA CORTE, Un

Comedia famosa, El negro del cuerpo blanco y el esclavo de su honra/ de un ingenio de esta corte.- En Madrid: 
en la imprenta de Antonio Sanz..., 1743.— [32] págs.; 4. ${ }^{\circ}$

Tít. tomado de la primera pág.

El pie de imprenta consta en colofón.

Texto a dos col., 48 líneas y reclamos.

Sign.: A-D4

T-73/28

82

InGENIO DE ESTA CORTE, Un

Comedia famosa El triunfo del Ave Maríal de un ingenio de esta Corte.- Hallaráse... en Madrid: en la imprenta de Antonio Sanz..., 1754.— 36 págs.; 4. ${ }^{\circ}$

Precede al tít.: «Núm. 127».

Tít. tomado de la primera pág.

El pie de imp. consta en colofón.

Sign.: A-D4, E2

Texto a dos col., 48 líneas y reclamos.

$\mathrm{T}-70 / 1(05)$

83

INGENIO DE ESTA CORTE, Un

Comedia nueva. Amor destrona monarcas y Rey muerto por amor/ de un Ingenio Valenciano.-Barcelona: por Francisco Genéras,...: Se hallará en Valencia en la Tienda de Francisco Navarro..., 1778. - 38 págs.; $4 .^{\circ}$

Precede al tít.: «Núm».

Tít. tomado de la primera pág.

Datos de publicación tomados del colofón.

Sign.: A-D, E3

Texto a dos col. y reclamos.

T-68/39

84

Introducción para la comedia intitulada La fianza satisfecha: que se ha de repre- sentar el día 4 de setiembre de 1772 , en honra y gloria del gran doctor de la Iglesia San Agustín. - Cervera: en la Imprenta de la Real y Pontificia Universidad, 1772.- [8] págs.; 4. ${ }^{\circ}$

Texto a dos col., orla que enmarca el texto en todas las páginas, reclamos.

Enc. con otras obras de teatro, bajo el tít. «Comedias» en el lomo.

T-70/1(01)

\section{5}

Landeras Velasco, José

Saynete, intitulado La casa de los abates locos: representado en los teatros de esta Corte para diez personas. - En Madrid: [Benito Cano] Se hallará en la Librería de Quiroga..., 1791.— 12 págs.; 4. ${ }^{\circ}$

Autor obtenido de Fernández Gómez.

Sign.: A6

Texto a dos col.

Grab. xil. en port.

T-76/41

\section{6}

Lово, Eugenio Gerardo (1679-1750)

Comedia Famosa. El mas justo rey de Grecial de Don Eugenio Gerardo Lobo.[Barcelona: Juan Francisco Piferrer, $c a$. 1800].— 32 págs.; $4 .^{\circ}$

Sign.: A-D4

$\mathrm{T}-76 / 1$

87

Martínez De Meneses, Antonio (1608-1661?)

Comedia Famosa, El tercero de su afrenta: fiesta que se hizo a su majestad en el Real Palacio/ de Don Antonio Martí- 
nez.- En Madrid: en la imprenta de Antonio Sanz, 1756. - 32 págs.; 4. ${ }^{\circ}$

Tít. tomado de la primera pág.

Precede al tít.: «Núm. 126».

Datos de publicación tomados del colofón.

Sign.: A-C4, D2

Texto a dos col., 48 líneas y reclamos.

$\mathrm{T}-70 / 1(06)$

88

Matos Fragoso, Juan de

Comedia famosa. El Job de las mugeres: Santa Isabel, Reyna de Ungría/ de don Juan de Matos Fragoso._- Sevilla: en la Imprenta de Joseph Padrino, [17--?].28 págs.; 4. ${ }^{\circ}$

Tít. tomado de la primera pág.

Precede al tít.: «Núm. 102».

Joseph Padrino ejerce ca.: 1748-1765.

Los datos de publicación constan en el colofón.

Sign.: A-C4, D2

Texto a dos col.

$\mathrm{T}-76 / 3$

89

Matos Fragoso, Juan de

Comedia Famosa. El Job de las mugeres Sta. Isabel, reyna de Ungría/ de D. Juan de Matos. - Madrid: en la imprenta de Antonio Sanz, 1755.— 32 págs.; 4. ${ }^{\circ}$

Precede al tít.: «Núm. 70».

Tít. tomado de la primera pág.

Datos de pie de imprenta tomados del colofón.

Sign.: A-C4, D3

Texto a dos col., 49 líneas y reclamos. $\mathrm{T}-70 / 1(04)$
90

Matos Fragoso, Juan de

Comedia famosa, Oponerse a las estrellas/ de Don Juan de Matos Fragoso, D. Antonio Martínez y D. Agustín Moreto.—En Valencia: en la imprenta de la Viuda de Joseph de Orga..., 1763._ 36 págs.; $4 .^{\circ}$

Precede al tít.: «Núm. 48».

Tít. tomado de la primera pág.

Datos de publicación tomados del colofón.

Sign.: A-D4, E2

Texto a dos col., 48 líneas y reclamos.

T-68/57

91

Matos Fragoso, Juan de

El marido de su madre. San Gregorio. Comedia famosa/ de don Juan de Matos Fragoso. - Sevilla: por Francisco de Leefdael, [17--?].— 32 págs.; 4. ${ }^{\circ}$

Tít. tomado de la primera pág.

Precede al tít.: «Núm. 110».

Los datos de publicación constan en el colofón.

Sign.: A-D4

Texto a dos col.

T-77/20

92

Mira de Amescua, Antonio (1574-1644)

Comedia famosa. Galán, valiente y discreto/ del doctor Mirademescua.Barcelona: por Francisco Suria y Burgada..., [17--?].— [32] págs.; 4. ${ }^{\circ}$

Datos de publicación tomados del colofón. Francisco Suriá y Burgada ejerció en Barcelona $c a .:$ 1770-1805.

Sign.: A-D4 
Texto a dos col.

Precede al tít.: «Núm. 160».

T-76/8

93

Molina, Tirso de (1579-1648)

Comedia famosa. La prudencia en la muger/ del maestro Tirso de Molina.Madrid: A costa de dicha Doña Theresa de Guzmán..., [17--?].— 44 págs.; 4. ${ }^{\circ}$

Tít. tomado de la primera pág.

El pie de imp. consta en colofón.

Sign.: A-E4, F2

Texto a dos col. y en verso, 49 líneas y reclamos.

$\mathrm{T}-70 / 1(08)$

94

Molina, Tirso de (1579-1648)

Comedia sin fama. El pretendiente al revés/ del maestro Tirso de Molina.- En Madrid: a costa de... Doña Theresa de Guzman, [17--?].— 43 págs.; 4. ${ }^{\circ}$

Precede al tít.: «Núm. 65».

Tít. tomado de la primera pág.

Pie de imp. tomado del colofón.

Sign.: A-E4, F2

Texto a dos col. y reclamos.

T-73/04

95

Monroy y Silva, Cristóbal de

Comedia famosa. Mudanzas de la fortuna, y firmezas del amor/ de... Christoval de Monroy y Silva. - En Valencia: en la Imprenta de la Viuda de Joseph de Orga..., 1768.- 28 págs.; 4. ${ }^{\circ}$

Precede al tít.: «Núm. 131».

Tít. tomado de la primera pág.
Datos de publicación tomados del colofón.

Sign.: A-C4, D2

Texto a dos col.

T-68/21

96

Monroy y Silva, Cristóbal de

Las mocedades del Duque de Ossuna: Comedia famosa/ de Don Christoval de Monroy.- En Sevilla: en la imprenta de Joseph Navarro y Armijo..., [17--?].- 24 págs.; $4 .^{\circ}$

Pie de imp. tomado del colofón.

Sign.: A4, A4[sic B4]-C4

Texto a dos col.

T-76/29

97

Morales, Cristóbal

Comedia famosa. El renegado del cielo/ de Don Christoval de Morales.- En Madrid: en la imprenta de Antonio Sanz..., 1735.- [28] págs.; 4. ${ }^{\circ}$

Precede al tít.: «Núm. 89».

El pie de imprenta consta en colofón.

Texto a dos col., 49 líneas y reclamos.

Sign.: A-C4, D2

$\mathrm{T}-73 / 43$

98

Moreto, Agustín (1618-1669)

Comedia famosa. Amor y obligación/ De Don Agustín Moreto.- En Sevilla: en la Imprenta de Joseph Padrino..., [17--?].— 28 págs.; 4. ${ }^{\circ}$

Según Gutiérrez del Caño, José Padrino, ejerce $c a$. 1748-1775.

Tít. tomado de la primera pág.

Precede al tít.: «Núm. 119». 
Texto a dos col.

Sign.: A-C4, D2

T-76/47

99

Moreto, Agustín (1618-1669)

Comedia famosa. El defensor de su agravio/ de don Augustín Moreto.-Sevilla: en la imprenta de Joseph Padrino..., [17--?].— 28 págs.; 4. ${ }^{\circ}$

Tít. tomado de la primera pág.

Precede al tít.: «Núm. 58».

Pie de imp. consta en colofón.

Joseph Padrino ejerce $c a$. 1748-1775, según Gutiérrez del Caño.

Sign.: A-C4, D2

Texto a dos col.

T-76/17

100

Moreto, Agustín (1618-1669)

Comedia famosa. La fingida Arcadial de Don Agustín Moreto.- En Barcelona: Por Juan Serra, y Nadal...: a costas de la Compañía, [17--?].— [32] págs.; 4. ${ }^{\circ}$

Tít. tomado de la primera pág.

Precede: «Núm. 184».

El pie de imp. consta en colofón.

Fechas de la actividad conocida del imp.: 1789-1796

Sign.: A-D4

Texto a dos col.

T-76/34

101

Moreto, Agustín (1618-1669)

Comedia famosa. Industrias contra finezas/ de Don Agustín Moreto.- Barcelona: por Juan Serra y Centené, impresor y librero..., [17--?].— [32] págs.; 4. ${ }^{\circ}$

Precede al tít. «Núm. 190».

Juan Centené ejerce ca. 1784-1788.

El pie de imp. consta en colofón.

Sign.: A-D4

Texto a dos col.

T-76/18

102

Moreto, Agustín (1618-1669)

Comedia famosa. El valiente justiciero/ de don Agustín Moreto.- Barcelona: en la imprenta de Joan Nadal...: a costas de la Compañía, 1772.— [32] págs.; 4. ${ }^{\circ}$

Tít. tomado de la primera pág.

Precede al tít.: «Núm. 182».

El pie de imp. consta en colofón.

T-76/24

103

Moreto, Agustín (1618-1669)

Entremés de la mariquita/ de D. Agustín Moreto.- [S. 1.: s. n., 17--?].— 8 págs.; 8. ${ }^{\circ}$

Tít. tomado de la primera pág.

$\mathrm{T}-77 / 4(05)$

104

Moreto, Agustín (1618-1669)

La gran comedia, Como se vengan los nobles/ de Don Agustín Moreto.Madrid: Juan Sanz, [17--?].- [32] págs.; $4 .^{\circ}$

Palau, 182577.

Tít. tomado de la primera pág.

Precede al tít.: «Núm. 281».

Pie de imp. tomado de Palau.

Sign.: A-D4 
Texto a dos col.

$\mathrm{T}-76 / 33$

105

Moreto, Agustín (1618-1669)

El lego del Carmen San Franco de Sena: comedia famosal de Don Agustín Moreto._ En Sevilla: por Francisco de Leefdael, [17--?].— 32 págs.; 4. ${ }^{\circ}$

El pie de imprenta consta en colofón.

Según Gutiérrez del Caño Leefdael imprime en Sevilla ca. 1701-1727.

Texto a dos col.

T-76/53

106

Opera, intitulada: El Amor a todos vence: ejecutada en la muy noble, y leal ciudad de Sevilla, el dia 22 de marzo de 1761._En Sevilla: por Joseph Padrino, [17--?].— 24 págs.; 4. ${ }^{\circ}$

Según Gutiérrez del Caño, José Padrino imprime en Sevilla ca. 1748-1775.

Sign.: A-C4

Texto a dos col.

Port. con orla tip.

T-76/54

107

Pérez de Montalván, Juan (1602-1638)

Comedia famosa Los amantes de Teruel/ del doctor Juan Pérez de Montalván.En Sevilla: en la imprenta de Joseph Padrino..., [17--?].— 28 págs.; 4. ${ }^{\circ}$

Precéde al tít.: «Núm. 165».

Según Gutiérrez del Caño, José Padrino ejerce $c a$. 1748-1775.

Sign.: A-C4, D2

Texto a dos col.
$\mathrm{T}-76 / 12$

108

Pérez de Montalván, Juan (1602-1638)

Comedia famosa. Como a padre y como a rey/ del doctor Juan Pérez de Montalván.- Barcelona: por Juan Serra, impresor, [17--?].— [32] págs.; 4. ${ }^{\circ}$

Precede a tít.: «Núm. 228».

Pie de imp. tomado del colofón.

Fechas de la actividad conocida del imp.: 1789-1796.

Sign.: A-D4

T-76/20

109

Pérez de Montalván, Juan (1602-1638)

Comedia famosa. La gitana de Menfis Santa María Egipcíaca/ del Doct. D. Juan Pérez de Montalván._- Madrid: en la imprenta de Antonio Sanz, en la plazuela de la calle de la Paz, 1756. 32 págs.; 4. ${ }^{\circ}$

Precede al tít.: «Núm. 159».

Tít. tomado de la primera pág.

Datos de publicación en colofón.

Sign.: A-D4

Texto a dos col., 48 líneas y reclamos.

$\mathrm{T}-70 / 1(03)$

110

Pérez de Montalván, Juan (1602-1638)

Comedia famosa. El mariscal de Virón/ de Don Juan Pérez Montalván.—En Sevilla: por Pedro Joseph Díaz, Impressor y Mercader de Libros..., [17--?].— 28 págs.; $4 .^{\circ}$

Sign.: A-C4, D2

$\mathrm{T}-76 / 4$ 


\section{1}

Pérez de Montalván, Juan (1602-1638)

Comedia famosa. La puerta Macarena: primera parte/ del doctor Juan Pérez de Montalván._- En Sevilla: en la imprenta de Joseph Padrino..., [17--?].— 28 págs.; $4 .^{\circ}$

Tít. tomado de la primera pág.

Precede al tít.: «Núm. 90».

Según Gutiérrez del Caño, José Padrino, ejerce $c a$. 1748-1775.

Sign.: A-C4, D2

Texto a dos col.

T-76/51(1)

112

Pérez de Montalván, Juan (1602-1638)

Comedia famosa. La puerta Macarena: segunda parte/ del doctor Juan Pérez de Montalván. - En Sevilla: en la imprenta de la Viuda de Francisco Lorenzo de Hermosilla..., [17--?].28 págs.; 4. ${ }^{\circ}$

Tít. tomado de la primera pág.

Precede al tít.: «Plieg. 3 y med. Núm. 11». Sign.: A-C4, D2

Texto a dos col.

$\mathrm{T}-76 / 51(2)$

\section{3}

Pieza heroyca en un acto: El Telémaco.-

[Madrid?: s. n.]: Se hallará esta en la librería de Cerro con la colección de las nuevas, [17--?].- 11 págs.; $4 .^{\circ}$

Tít. tomado de la primera pág.

Sign.: A4, B2

Texto a dos col., 48 líneas y reclamos. $\mathrm{T}-68 / 55(02)$
114

RoA, Gabriel de

El premiar al liberal, por rescatar su fortuna: comedia famosa/ de Don Gabriel de Roa.- En Sevilla: por la Viuda de Francisco Leefdael, en la Casa del Correo Viejo, [17--?].— 32 págs.; 4. ${ }^{\circ}$

Precede al tít.: «Núm. 30».

Pie de imprenta tomado del colofón.

Según el ICCU, esta obra estaría publicada entre 1729-1733.

Sign.: A-D4

Texto a dos col.

$\mathrm{T}-78 / 12$

115

Rodríguez de Arellano, Vicente

Comedia nueva. La muger de dos maridos: en tres actos/ por D.V.R.D.A.- [S.l.: s. n., 17--?].- 30 págs.; $22 \mathrm{~cm}$.

Tít. tomado de la primera pág.

Precede al tít.: «Núm. 5».

Incompleto a partir de pág. 30 .

T-76/9

116

Rodríguez de Arellano, Vicente

El esplín: pieza en un acto/ por D. Vicente Rodríguez de Arellano.- Barcelona: en la oficina de Pablo Nadal, 1798.14 págs.; $4 .^{\circ}$

Junto a la publicación lista de los libros y comedias que se hallan en la oficina de Pablo Nadal en Barcelona.

Precede al tít.: «Núm. 56».

Datos de publicación tomados del colofón.

Sign.: A4, B3

Texto a dos col. y reclamos.

T-73/52 


\section{7}

Rodríguez de Arellano, Vicente

El pintor fingido: comedia en tres actos/ por Don Vicente Rodriguez Arellano; representada por la Compañía de Luis Navarro.- Madrid: en la imprenta de Don Fermín Tadeo Villalpando: se hallará en la Librería de Cerro..., 1800.— 28 págs.; 4. ${ }^{\circ}$

Sign.: A-C4, D2

$\mathrm{T}-73 / 54$

\section{8}

Rojas Zorrilla, Francisco de (1607-1648)

Comedia. Casarse por vengarse/ de Don Francisco de Roxas.- [Madrid]: Se hallará en la librería de Quiroga..., 1793.— 32 págs.; $4 .^{\circ}$

Tít. tomado de la primera pág.

Datos de publicación tomados del colofón.

Sign.: A-D4

T-68/37

\section{9}

Rojas Zorrilla, Francisco de (1607-1648)

Comedia famosa. Los aspides de Cleopatral de don Francisco de Roxas. - Madrid: en la imprenta de Antonio Sanz..., 1742.— [36] págs.; 4. ${ }^{\circ}$

Tít. tomado de la primera pág.

El pie de imp. consta en colofón.

Sign.: A-D4, E2

Texto a dos col., 48 líneas y reclamos.

$\mathrm{T}-73 / 38$

120

Rojas Zorrilla, Francisco de (1607-1648)

Comedia famosa. Progne, y Filomena/ de don Francisco de Roxas.- Barcelona: por Francisco Suriá, [1770-1805].[36] págs.; 4. ${ }^{\circ}$

Precede al tít.: «Núm. 145».

Tít. tomado de la primera pág.

Datos de publicación en colofón.

Francisco Suriá y Burgada ejerce como impresor ca.: 1770-1805.

Sign.: A-D4, E2

Texto a dos col.

T-68/47

\section{1}

Rojas Zorrilla, Francisco de (1607-1648)

Comedia famosa. Los trabajos de Tobías/ de don Francisco de Roxas.- Madrid: en la imprenta de Antonio Sanz..., 1755.— 40 págs.; $4 .^{\circ}$

Precede al tít.: «Núm. 216».

Tít. tomado de la primera pág.

El pie de imp. consta en colofón.

Sign.: A-E4

Texto a dos col., 48 líneas y reclamos.

$\mathrm{T}-70 / 1(07)$

122

Salazar Torres, Agustín de (1642-1675)

Comedia famosa. También se ama en el abysmo: Fiestas de la Zarzuela, a los años de la Reyna Nuestra Señora Doña María Ana de Austria/ de Don Agustín de Salazar.- Salamanca: en la Imprenta de la Santa Cruz..., [1701-1800?].— 32 págs.; 4. ${ }^{\circ}$

Tít. tomado de la primera pág.

Precede al tít.: «Núm.160».

Datos de publicación tomados del colofón.

Sign.: A-D4

T-68/35 
123

Salvo y Vela, Juan (?-1720)

El Maxico de Salerno: Comedia famosal de don Juan Salvo y Vela; segunda parte._ En Sevilla: Imprenta Real, [ca.1750].—28 págs.; 4. ${ }^{\circ}$

Tít. tomado de la primera pág.

Precede al tít.: «Núm. 282».

Sign.: A-C4, D2

Texto a dos col.

T-77/16(1)

124

Salvo y Vela, Juan (? - 1720)

El Maxico de Salerno: Comedia famosal de don Juan Salvo y Vela; tercera parte.- En Sevilla: Imprenta Real, [ca. 1750].—2 28 págs.; 4. ${ }^{\circ}$

Tít. tomado de la primera pág.

Precede al tít.: «Núm. 283».

Sign.: A-C4, D2

Texto a dos col.

T-77/16(2)

125

Salvo y Vela, Juan (? - 1720)

El Maxico de Salerno: Comedia famosal

de don Juan Salvo y Vela; quarta parte._ En Sevilla: Imprenta Real, [ca. 1750].—2 28 págs.; 4. ${ }^{\circ}$

Tít. tomado de la primera pág.

Precede al tít.: «Núm. 282».

Sign.: A-C4, D2

Texto a dos col.

T-77/16(3)

126

Saynete La hija embustera, y la madre más que ella.— Madrid: [Benito Cano]
Se hallará en la Librería de Quiroga..., 1791.— 8 págs.; $4 .^{\circ}$

Texto a dos col., 38 líneas y reclamos.

T-73/57

127

Saynete, intitulado El abate y albañil: representado en los teatros de esta corte para cinco personas. - Madrid: [Benito Cano] Se hallará en la Librería de Quiroga..., 1791.— 12 págs.; $4 .^{\circ}$

Texto a dos col., 38 líneas y reclamos.

Sign.: A6

Grab. xil. en port.

T-73/05

128

Saynete, intitulado Amo y criado en la casa de vinos generosos: representado en los teatros de esta corte para nueve personas._- Madrid: [Benito Cano] Se hallará en la Librería de Quiroga..., 1791.— 11 págs.; $4 .^{\circ}$

Texto a dos col., 40 líneas y reclamos.

Sign.: A6

Grab. xil. en port.

$\mathrm{T}-73 / 06$

129

Saynete, intitulado Los áspides: representado en los teatros de esta Corte para seis personas.—En Madrid: [Benito Cano] Se hallará en la Librería de Quiroga..., 1791._- 7 págs.; $4 .^{\circ}$

Sign.: A2

Texto a dos col.

Grab. xil. en port.

$\mathrm{T}-76 / 45$ 
Saynete, intitulado La astucia de la alcarreña: representado en los teatros de esta Corte para seis personas._- En Madrid: [Benito Cano] Se hallará en la Librería de Quiroga..., 1791.— 11 págs.; 4. ${ }^{\circ}$

Sign.: A6

Texto a dos col.

Grab. xil. en port.

T-76/49

\section{1}

Saynete, intitulado El caballero de Siguenza, Don Patricio Lucas: representado en los teatros de esta corte, para diez personas._- Madrid: [Benito Cano] Se hallará en la Librería de Quiroga..., 1791.— 12 págs.; 4. ${ }^{\circ}$

Texto a dos col., 39 líneas y reclamos.

Sign.: A6

Grab. xil. en port.

T-73/02

\section{2}

Saynete, intitulado El ciego por su provecho: representado en los teatros de esta corte para ocho personas.- Madrid: [Benito Cano] Se hallará en la Librería de Quiroga..., 1791.— 11 págs.; 4. ${ }^{\circ}$

La publicación incluye lista de Saynetes impresos que se hallan en dicha Librería.

Texto a dos col., 36 líneas y reclamos.

Sign.: A6

Grab. xil. en port.

$\mathrm{T}-73 / 40$

\section{3}

Saynete, intitulado Los criados y el enfermo: representado en los teatros de esta Corte. - En Madrid: [Benito Cano] Se hallará en la Librería de Quiroga..., 1791._- 12 págs.; $4 .^{\circ}$

Sign.: A6

Texto a dos col.

Grab. xil. en port.

T-76/27

\section{4}

Saynete intitulado El día de lotería, primera parte: representado en los teatros de esta corte para diez personas.Madrid: [Benito Cano] en la Librería de Quiroga..., 1791.— 12 págs.; 4. ${ }^{\circ}$

Texto a dos col., 36 líneas y reclamos.

Sign.: A6

Grab. xil. en port.

$\mathrm{T}-73 / 60$

\section{5}

Saynete, intitulado El examen de cortejos, y aprobacion para serlo: representado en los teatros de esta corte para ocho personas.- Madrid: [Benito Cano] Se hallará en la Librería de Quiroga..., 1791._8 págs.; 4. ${ }^{\circ}$

Texto a dos col., 38 líneas y reclamos.

Sign.: A4

Grab. xil. en port.

T-73/62

136

Saynete, intitulado Los efectos de un cortejo, y criada vergonzosa: representado en los teatros de esta corte para nueve personas.- Madrid: [Benito Cano] se 
hallará en la Librería de Quiroga..., 1791._- 12 págs.; $4 .^{\circ}$

Grab. xil. en port.

Texto a dos col. y reclamos.

Sign.: A6

T-73/22

137

Saynete, intitulado Los gansos: representado en los teatros de esta corte para doce personas. - Madrid: [Benito Cano] en la Librería de Quiroga..., 1791._11 págs.; $4 .^{\circ}$

Texto a dos col., reclamos.

Sign.: A6

Grab. xil. en port.

T-73/16

\section{8}

Saynete, intitulado Juan Juye, y la propietaria: representado en los teatros de esta corte para siete personas.-Madrid:

[Benito Cano] Se hallará en la Librería de Quiroga..., 1791.— 8 págs.; 4. ${ }^{\circ}$

Texto a dos col., 38 líneas y reclamos.

Sign.: A4

Grab. xil. en port.

T-73/29

\section{9}

Saynete, intitulado Los locos de Mayor Marca: representado en los teatros de esta corte para once personas.-Madrid: [Benito Cano] Se hallará en la Librería de Quiroga..., 1791.— 8 págs.; 4. ${ }^{\circ}$

Texto a dos col., 39 líneas y reclamos.

Sign.: A4

T-73/33
140

Saynete, intitulado Los locos de Sevilla: representado en los teatros de esta corte para ocho personas. - Madrid: [Benito Cano] Se hallará en la Librería de Quiroga..., 1791.— 8 págs.; $4 .^{\circ}$

Texto a dos col., 38 líneas y reclamos.

Sign.: A4

Grab. xil. en port.

T-73/01

141

Saynete, intitulado El page pedigueño: representado en los teatros de esta corte para nueve personas. - Madrid: [Benito Cano] Se hallará en la Librería de Quiroga..., 1791.— 8 págs.; 4. ${ }^{\circ}$

Texto a dos col., 35 líneas y reclamos.

Sign.: A4

Grab. xil. en port.

T-73/63

142

Saynete, intitulado Los payos astutos: representado en los teatros de esta corte para seis personas. - Madrid: [Benito Cano] Se hallará en la Librería de Quiroga..., 1791.— 12 págs.; 4. ${ }^{\circ}$

Texto a dos col., reclamos.

Sign.: A6

Grab. xil. en port.

T-73/25

143

Saynete, intitulado Perico el empedrador ó Los ciegos hipócritas y embusteros: representado en los teatros de esta corte para seis personas. - Madrid: [Benito Cano] 
Se hallará en la Librería de Quiroga..., 1791.— 12 págs.; 4. ${ }^{\circ}$

Texto a dos col., 39 líneas y reclamos.

Sign.: A6

Grab. xil. en port.

$\mathrm{T}-73 / 56$

144

Saynete, intitulado El pleyto del pastor: representado en los teatros de esta corte para diez personas. - Madrid: [Benito Cano] Se hallará en la Librería de Quiroga..., 1791.— 12 págs.; $4 .^{\circ}$

Texto a dos col., 36 líneas y reclamos.

Sign.: A6

Grab. xil. en port.

T-73/30

\section{5}

Saynete, intitulado La quinta esencia de la miseria: representado en los teatros de esta corte para once personas._- Madrid: [Benito Cano] Se hallará en la Librería de Quiroga..., 1791.— 12 págs.; 4. ${ }^{\circ}$

Texto a dos col., 37 líneas y reclamos.

Sign.: A6

Grab. xil. en port.

T-73/55

146

Saynete, intitulado El sastre y su hijo: representado en los teatros de esta corte para diez personas. - Madrid: [Benito Cano] Se hallará en la Librería de Quiroga..., 1791._- 11 págs.; 4. ${ }^{\circ}$

Texto a dos col., 37 líneas y reclamos.

Sign.: A6

Grab. xil. en port.

$\mathrm{T}-73 / 36$
147

Saynete, intitulado Los sies del mayordomo Don Ciriteca: representado en los teatros de esta corte para nueve personas.- Madrid: [Benito Cano] Se hallará en la Librería de Quiroga..., 1791._11 págs.; $4 .^{\circ}$

Texto a dos col., 38 líneas y reclamos.

Sign.: A6

Grab. xil. en port.

T-73/34

148

Saynete, intitulado El Tonto alcalde discreto: representado en los teatros de esta corte para once personas.- Madrid: [Benito Cano] Se hallará en la Librería de Quiroga..., 1791.— 12 págs.; 4. ${ }^{\circ}$

Texto a dos col., 39 líneas y reclamos.

Sign.: A6

Grab. xil. en port.

$\mathrm{T}-73 / 53$

149

Saynete, intitulado Los tres novios imperfectos, sordo, tartamudo y tuerto: representado en los teatros de esta corte para doce personas. - Madrid: [Benito Cano] Se hallará en la Librería de Quiroga..., 1791.— 12 págs.; 4. ${ }^{\circ}$

Texto a dos col., 38 líneas y reclamos.

Sign.: A6

Grab. xil. en port.

T-73/32

150

Saynete, intitulado El zeloso: representado en los teatros de esta corte para cinco personas.- Madrid: [Benito Cano] Se 
hallará en la Librería de Quiroga..., 1791.— 8 págs.; 4. ${ }^{\circ}$

Texto a dos col., 38 líneas y reclamo.

Sign.: A4

Grab. xil. en port.

T-73/51

151

Saynete nuevo, intitulado La burla del posadero y castigo de la estafa.Madrid: [Benito Cano] en la Librería de Quiroga..., 1793.— Págs. 25-32; 4. ${ }^{\circ}$

Texto a dos col., reclamos.

Sign.: D4

Grab. xil. en port.

$\mathrm{T}-73 / 24$

152

Saynete nuevo El secreto de dos malo es de guardar: para tres personas.- En Madrid: [Benito Cano] Se hallará en la Librería de Quiroga..., 1791._-8 págs.; $4 .^{\circ}$

Sign.: A4

Texto a dos col.

Grab. xil. en port.

T-76/57

\section{3}

Solís, Antonio de (1610-1686)

Comedia famosa. El alcazar del secreto/ de Don Antonio Solis. - Madrid: en la imprenta de Antonio Sanz..., 1731._[36 págs.]; 4. ${ }^{\circ}$

Tít. tomado de la primera pág.

Precede al tít.: «Núm. 160».

Datos de publicación en colofón.

Sign.: A-D4, E2

Texto a dos col.
T-76/5

154

Solís, Antonio de (1610-1686)

Comedia famosa. Amparar al enemigo/ de Don Antonio Solís. - Madrid: en la imprenta de [Antonio Sanz] la plazuela de la calle de la Paz, 1729._— [32 págs.]; $4 .^{\circ}$

Precede al tít.: «Núm. 45».

Tít. tomado de la primera pág.

Datos de publicación en colofón.

Sign.: A-D4

Texto a dos col., 48 líneas y reclamos.

T-73/41

\section{5}

Sueños hay que lecciones son, o efectos del desengaño: drama alegorico en cinco actos/ refundido por D. M. A. Igual.Barcelona: por Francisco Suriá y Burgada: a costas de la Compañía, [17--?].— 24 págs.; 4. ${ }^{\circ}$

Francisco Suriá y Burgada ejerce como impresor ca.: 1770-1805.

Datos de publicación tomados del colofón. Sign.: A-C4

Texto a dos col., 49 líneas, reclamos.

Tít. tomado de la primera pág.

Sello de la Librería de Josep Carlos, en Valencia, calle de la Lonja de la Seda.

T-68/53(2)

156

Tres Ingenios

Comedia famosa. A un tiempo rey, y vassallo/ de tres ingenios. - Madrid:... en la imprenta de Antonio Sanz..., 1745.[24] págs.; 4. ${ }^{\circ}$ 
Precede al tít.: «Núm. 6».

Tít. tomado de la primera pág.

El pie de imp. consta en colofón.

Sign.: A-C4

Texto a dos col., 48 líneas y reclamos.

$\mathrm{T}-73 / 39$

157

Tres Ingenios

Comedia famosa. El hijo pródigo/ de tres ingenios. - Madrid: en la imprenta de D. Antonio Sanz, en la plazuela de la calle de la Paz, 1785.— 32 págs.; 4. ${ }^{\circ}$

Precede al tít.: «Núm. 67».

Urzáiz Tortajada, Héctor, «Catálogo de autores teatrales del siglo XVII», t. II, pág. 429, señala como autores a Matos Fragoso, Moreto y Cáncer.

Tít. tomado de la primera pág.

Pie de imp. consta en colofón.

T-70/1(10)

158

Trigueros, Cándido María

Sancho Ortíz de las Roelas: Tragedia/ arreglada por Don Candido Maria Trigueros.- En Valencia: En la Imprenta de Joseph de Orga...; y en Madrid: Librería de Quiroga, 1802.-28 págs.; 4. ${ }^{\circ}$

Es una refundición de La Estrella de Sevilla, de Lope de Vega.

Tít. tomado de la primera pág.

Precede al tít.: «Núm. 330».

Datos de publicación tomados del colofón.

Sign.: A-C4, D2

Texto en dos col., 48 líneas, reclamos.

159

Valladares De Sotomayor, Antonio
Comedia Nueva Original El católico Recaredo/su autor Don Antonio Valladares de Sotomayor. - En Madrid: en la Imprenta y Librería de Don Isidro López..., [17--?].—36 págs.; 4. ${ }^{\circ}$

Tít. tomado del principio del texto.

Sign.: A-D4, E2

Texto a dos col.

T-76/11

160

VEGA, Lope de (1562- 1635)

La boba para los otros, y discreta para si: Comedia famosa/ de Lope de Vega Carpio.— [S. l.: s. n., s. a].— [43] págs.; 4. ${ }^{\circ}$

Tít. tomado de la primera pág.

Texto a dos col. y en verso, 41 líneas y reclamos.

Sign.: A-E4, F2

T-73/37

\section{1}

VEGA, Lope de (1562- 1635)

Comedia famosa David perseguido y montes de Gelboél de Lope de Vega Carpio.- Barcelona: en la imprenta de Juan Nadal: a costas de la Compañía, 1773. - [28] h.; $4 .^{\circ}$

Tít. tomado de la primera pág.

Precede al tít.: «Núm. 183».

El pie de imp. consta en colofón.

T-76/14

162

VEGA, Lope de (1562- 1635)

Comedia famosa de El Gallardo Catalan/ de Lope de Vega Carpio.- [S. l.: s. n., s. a].- [63] págs.; 4. ${ }^{\circ}$

Tít. tomado de la primera pág. 
Texto a dos col. y reclamos.

Sign.: I-M8

$\mathrm{T}-73 / 17$

163

VEGA, Lope de (1562- 1635)

Comedia famosa del mayorazgo dudoso/ de Lope de Vega Carpio.- [S.1.: s.n., 17--?].— [56] págs.; 4. ${ }^{\circ}$

Texto a dos col.

Sign.: N-Q4

Cabecera con orla tipográfica en primera pág.

T-76/7

164

VEGA, Lope de (1562- 1635)

Comedia famosa Servir con mala estrella/ de Lope de Vega Carpio.- [S. 1.: s. n., s. a].— 40 págs.; 4. ${ }^{\circ}$

Tít. tomado de la primera pág.

Texto a dos col., 42 líneas y reclamos.

Sign.: A-E4

$\mathrm{T}-73 / 45$

Índice de títulos

A lo que obligan los zelos: 59

A un tiempo rey, y vassallo: 156

Abate y albañil, El: 127

Alcazar del secreto, El: 153

Almacen de novias, El: 46

Amantes de Teruel, Los: 107

Amigo, amante, y leal: 19

Amo y criado en la casa de vinos generosos: 128

Amor a todos vence, El: 106
Amor destrona monarcas y Rey muerto por amor: 83

Amor y obligación: 98

Amparar al enemigo: 154

Antes que todo es mi amigo: 60

Arco de la paz del cielo, Sta. Barbara, El: 1

Aspides de Cleopatra: 119

Aspides, Los: 129

Astucia de la alcarreña, La: 130

Astucias de Luzbel contra las divinas profecias: 3

Avaricia castigada ó Los segundones, La: 47

Bandolera de Italia, La: 78

Basta callar: 20

Boba para los otros y discreta para si, La: 160

Burla del posadero y castigo de la estafa, La: 151

Caballero de Medina, El: 48

Caballero de Siguenza, Don Patricio Lucas, El: 131

Canas en el papel y dudoso en la venganza, Las: 6

Carlos Quinto sobre Tunez: 34

Casa de los abates locos, La: 85

Casado por fuerza, El:49

Casarse por vengarse: 118

Casero burlado, El: 50

Castigo en tres venganzas, Un: 7

Catalán Serrallonga y vandos de Barcelona, El: 41

Católico Recaredo, El: 159

Ciego por su provecho, El: 132

Cochero y monsieur corneta, El: 51

Como a padre y como a rey: 108

Como se vengan los nobles: 104

Con quien vengo vengo: 8

Criados y el enfermo, Los: 133 
Cuenta de propios y arbitrios, La: 52

Darlo todo, y no dar nada: 21

David perseguido y montes de Gelboé: 161

Defensa de Valencia y castigo de traydores: 40

Defensor de su agravio: 99

Dia de loteria, El: 134

Diablo predicador y mayor contrario amigo, El: 5

Domine Lucas, El: 35

Don Pedro Calderón de la Barca... 18

Duelo contra su dama, El: 4

Efectos de un cortejo, y criada vergonzosa, Los: 136

Enfermo fugitivo ó La geringa, El: 53

Entremés de la Duca: 62

Entremés de la mariquita: 103

Entremés de las conclusiones: 63

Entremés de los caldereros: 64

Entremés de los vicios patentes: 65

Entremés de trullo: 66

Entremés del gori-gori: 67

Entremés del molinero: 68

Entremés del pésame de Medrano: 69

Entremés La Requisitoria del borrico: 70

Entremés nuevo del capitán D. Samuel: 71

Escondido y la tapada, El: 23

Español Juan de Urbina, El: 74

Esplin, El: 116

Estatua de Prometeo: representose a los años de la Reyna Madre Nuestra Señora, La: 9

Exaltacion de la cruz, La: 24

Examen de cortejos, y aprobacion para serlo, El: 135

Falso nuncio de Portugal, El: 79

Fianza satisfecha, La: 84

Fiera, el rayo, y la piedra, La: 25

Fingida Arcadia, La: 100
Fuego de Dios en el querer bien: 26

Galán, valiente y discreto: 92

Gallardo Catalan, El: 162

Gansos, Los: 137

Gitana de Menfis Santa María Egipcíaca, La: 109

Gracioso engaño creido del duende fingido: 54

Gran comedia. La Desdicha de la voz, La: 22

Hados y lados hacen dichosos y desdichados: 80

Hannibal: 73

Hija embustera, y la madre mas que ella, La: 126

Hijo pródigo, El: 157

Industrias contra finezas: 101

Job de las mugeres, El: 88

Job de las mugeres: Sta. Isabel, reyna de Ungria, El. 89

Juan Juye, y la propietaria: 138

Juramento ante Dios y lealtad contra el amor; El: 42

Laurel de Apolo: Fiesta de Zarzuela, Transferida al Real Coliseo de Buen Retiro, $E l: 27$

Lego del Carmen San Franco de Sena, El: 105

Locos de Mayor Marca, Los: 139

Locos de Sevilla, Los: 140

Maestro de Alexandro, El: 61

Manolo, El: 55

Manolo: Tragedia para reir, ò Saynete para llorar: 45

Mañana sera otro dia: 33

Marido de su madre, El. San Gregorio: 91

Mariscal de Virón, El: 110

Mas justo rey de Grecia, El: 86

Maxico de Salerno, El:123, 124, 125 
Mayorazgo dudoso, El: 163

Mercader de Toledo: vara de medir, y acción del mejor testigo, El: 10

Mocedades del Duque de Ossuna, Las: 96

Morir en la Cruz con Christo: 77

Mudanzas de la fortuna, y firmezas del amor: 95

Muger de dos maridos, La: 115

Negro del cuerpo blanco y el esclavo de su honra, El: 81

Negro mas prodigioso, El: 58

No ay cosa como callar: 28

No hay cosa buena por fuerza: 75

No hay cosa como callar: 11

Oponerse a las estrellas: 90

Oveja contra el pastor, y el tyrano Boleslao, La: 2

Page pedigueño, El: 141

Para vencer a amor, querer vencerle: fiesta que se representó à sus Majestades en el salon de su Real Palacio: 12

Payos astutos, Los: 142

Perico el empedrador ó Los ciegos hipócritas y embusteros: 143

Pintor de su deshonra, El: 29

Pintor fingido, El: 117

Pleyto del pastor, El: 144

Posadera y el enemigo de las mugeres, La: 72

Premiar al liberal por rescatar su fortuna, El: 114

Pretendiente al revès, El: 94

Príncipe jardinero y mayor ciencia laureada, El: 43

Progne, y Filomena: 120

Prudencia en la muger, La: 93

Puerta Macarena, La: 111, 112

Purgatorio de San Patricio, El: 13
Purpura de la rosa, La: 14

Quinta esencia de la miseria, La: 145

Rayo de Andalucia y jenízaro de España, $E l: 56,57$

Renegado del cielo: 97

Rhadamisto y Zenobia: 44

Sancho Ortiz de las Roelas: 158

Sastre y su hijo, El: 146

Secreto a voces, El: 15

Secreto de dos malo es de guardar, El: 152

Segundo scipion: fiesta que se representò à los años del Rey nestro Señor Don Carlos Segundo, El: 30

Servir con mala estrella: 164

Sies del mayordomo Don Ciriteca, Los: 147

Sueños hay que lecciones son, o efectos del desengaño: 155

Tambien ay duelo en las damas: 31

Tambien por la voz hay dicha: 36,37

También se ama en el abysmo: 122

Telemaco, El: 113

Tercero de su afrenta, El: 87

Tonto alcalde discreto, El: 148

Trabajos de Tobias, Los: 121

Tragedia El Sacrificio de Ifigenia: en cinco actos, El: 38, 39

Tres justicias en una, Las: 16

Tres mayores prodigios: Fiesta que se representò à sus magestades, en el Real Sitio de la Casa del Campo, Los: 32

Tres novios imperfectos, sordo, tartamudo y tuerto, El: 149

Triunfo del Ave Maria, El: 82

Valiente justiciero, El: 102

Vida es sueño, La: 17

Virtud consiste en medio, el pródigo y rico avariento, La: 76

Zeloso, El: 150 